\title{
DISTRIBUTION OF RADIOCARBON AGES IN SOIL ORGANIC MATTER BY THERMAL FRACTIONATION
}

\begin{abstract}
Alain F Plante ${ }^{1}$ Steven R Beaupré2 $•$ Mark L Roberts $^{2}$ - Troy Baisden ${ }^{3}$
ABSTRACT. Radiocarbon analysis is an important tool in quantifying soil organic matter (SOM) dynamics within the terrestrial carbon cycle. However, there is increasing appreciation that representing SOM as a single, homogeneous pool with a single, mean ${ }^{14} \mathrm{C}$ concentration is inadequate. We investigate whether the differing patterns in $\mathrm{CO}_{2}$ release during rampedtemperature oxidation reflect organic matter of different ages, and hypothesize that thermally labile SOM (combusting at low temperatures) consists of younger carbon than thermally resistant organic matter. Topsoil samples under contrasting land uses (native vegetation and long-term cultivation) were selected for ${ }^{14} \mathrm{C}$ analysis before and after acid fumigation for the removal of carbonates. Results of bulk ${ }^{14} \mathrm{C}$ analyses showed a significant shift in ${ }^{14} \mathrm{C}$ age from $0.944 \mathrm{Fm}$ under native vegetation to $0.790 \mathrm{Fm}$ under cultivation. Four to 5 "fractions" associated with different $\mathrm{CO}_{2}$-evolution regions were identified by thermal analysis and analyzed for ${ }^{14} \mathrm{C}$ via modifications to NOSAMS' established "programmed temperature pyrolysis system," in which discrete $\mathrm{CO}_{2}$ fractions evolved during ramped-temperature oxidation were isotopically characterized by a microwave gas ion source (GIS) continuous-flow AMS (CFAMS) system. Results showed that while acid fumigation removed soil carbonates, the treatment also significantly altered the thermograms and inferred SOM composition. While direct attribution of ${ }^{14} \mathrm{C}$ values to individual peaks is somewhat confounded by overlapping temperature ranges for oxidation of unique populations of carbon, in general, thermally stable fractions of SOM appear to be ${ }^{14} \mathrm{C}$-depleted compared to thermally reactive (low temperature) fractions regardless of pretreatment.
\end{abstract}

\section{INTRODUCTION}

Radiocarbon analysis is an important tool in quantifying soil organic matter (SOM) dynamics within the terrestrial carbon cycle (Trumbore 2009). Measuring ${ }^{14} \mathrm{C}$ concentrations in bulk soil samples provides the "apparent" mean age or residence time of the associated organic matter. However, it is well known that SOM consists of a heterogeneous spectrum of materials, and that representing it as a single, homogeneous pool with a single, mean ${ }^{14} \mathrm{C}$ concentration is inadequate. Significant effort has gone into separating SOM into fractions with different relative biogeochemical stability, and thus ${ }^{14} \mathrm{C}$ concentrations. Trumbore and Zheng (1996) concluded that a combination of physical (by size or density) and chemical (acid and base hydrolysis) fractionation provides a useful means of separating labile and stable organic matter components prior to ${ }^{14} \mathrm{C}$ measurements. However, recent studies have demonstrated that acid hydrolysis residues may contain significant amounts of recent $\mathrm{C}$ inputs (Paul et al. 2006), and that density fractionation to isolate a labile pool may be confounded by the presence of black carbon (Murage et al. 2007). Overall, soil fractionation approaches have well-known limitations (e.g. von Lützow et al. 2007; Denef et al. 2009) but may still be useful to parameterize modelable pools (e.g. Smith et al. 2002).

As an alternative, thermal analysis techniques may be used to characterize the complete spectrum of SOM stability based on the hypothesized link between the thermal and biogeochemical stability of SOM (Plante et al. 2011). Previous studies have combined thermal analysis with stable isotope (e.g. ${ }^{13} \mathrm{C}$ and ${ }^{15} \mathrm{~N}$ ) analyses. For example, Dorodnikov et al. (2007) used thermal analysis (i.e. simultaneous thermogravimetry [TG] and differential scanning calorimetry [DSC]) to identify pools of SOM differing in thermal stability. Samples were subsequently combusted in a muffle furnace in a stepwise sequence, and the residues were analyzed for ${ }^{13} \mathrm{C}$ and ${ }^{15} \mathrm{~N}$ to determine SOM stability and turnover

\footnotetext{
${ }^{1}$ Dept. Earth and Environmental Science, University of Pennsylvania, 240 South 33rd Street, Hayden Hall, Philadelphia, Pennsylvania 19104-6316, USA. Corresponding author. Email: aplante@sas.upenn.edu.

${ }^{2}$ NOSAMS, Woods Hole Oceanographic Institution, 266 Woods Hole Rd. MS\#08, Woods Hole, Massachusetts 02543, USA.

${ }^{3}$ National Isotope Centre, GNS Science, PO Box 31-312, Lower Hutt, New Zealand.
}

(C) 2013 by the Arizona Board of Regents on behalf of the University of Arizona

Proceedings of the 21st International Radiocarbon Conference edited by A J T Jull \& C Hatté

RADIOCARBON, Vol 55, Nr 2-3, 2013, p 1077-1083 


\section{A F Plante et al.}

following a $\mathrm{C}_{3}-\mathrm{C}_{4}$ vegetation change. Other applications have involved direct instrument coupling and stable isotope analysis of the evolved gas (e.g. Lopez-Capel et al. 2006; Manning et al. 2008).

The coupling of thermal analysis techniques with ${ }^{14} \mathrm{C}$ analysis is significantly more technically challenging and expensive, and thus less frequently applied. Although stepwise heating of organic matter to monotonically higher temperatures extracts sufficiently massive fractions of carbon for subsequent AMS-based ${ }^{14} \mathrm{C}$ measurements (Wang et al., these proceedings), a constant temperature ramp rate permits both identification and isolation of unique subpopulations of carbon for ${ }^{14} \mathrm{C}$ analyses (Rosenheim et al. 2008). The aim of the current study was to demonstrate the proof of principle for a novel coupling of thermal analysis and ${ }^{14} \mathrm{C}$ analysis to generate more information about SOM stability than is possible from a single, bulk-soil ${ }^{14} \mathrm{C}$ value.

We subjected topsoils with contrasting land-use histories to ramped oxidation and compared their resulting thermograms and associated ${ }^{14} \mathrm{C}$ values to assess the efficacy of coupling ramped-thermal and ${ }^{14} \mathrm{C}$ analyses to characterize SOM stability. By coupling thermal and ${ }^{14} \mathrm{C}$ analyses, we seek to answer the question: Do the differing patterns in $\mathrm{CO}_{2}$ release during thermal analysis reflect SOM of different ages? We hypothesize that thermally labile organic matter (combusting at low temperatures) consists of younger, more ${ }^{14} \mathrm{C}$-enriched carbon than thermally resistant organic matter.

\section{METHODS}

Two soil samples were collected from Indian Head, Saskatchewan Canada $\left(50^{\circ} 32^{\prime} \mathrm{N}, 103^{\circ} 31^{\prime} \mathrm{W}\right)$. The samples were co-located and originated from the same grassland derived topsoil but were distinguished by contrasting histories dominated by native vegetation and long-term cultivation. The climate of the area is continental subhumid, with warm summers and cold winters. The mean annual temperature is $2{ }^{\circ} \mathrm{C}$, and mean annual precipitation is $427 \mathrm{~mm}$. The soil is characterized as a Udic Boroll in the US Soil Taxonomy (or Black Chernozem in the Canadian Soil Classification System), which developed on clayey lacustrine deposits underlain by till (Campbell et al. 1997). The soil under native vegetation was collected from an area with no known history of cultivation located between cultivated fields. The soil under long-term cultivation was managed as a fallow-spring wheat or fallow-wheat-wheat rotation using conventional tillage before 1957, and as a rotation experiment using a sequence of spring-wheat-based rotations including legumes and hay crops since 1957 (Campbell et al. 1997). Long-term cultivation decreased soil organic $\mathrm{C}$ concentrations from $4.4 \pm 0.6 \%$ to $2.7 \pm$ $0.1 \%$ and soil $\mathrm{N}$ concentrations from $0.4 \pm 0.06 \%$ to $0.3 \pm 0.01 \%$, while other soil characteristics remained essentially unchanged: $\mathrm{pH}=7.5$ and clay content of $63 \%$ (Campbell et al. 1997).

Surface litter and aboveground vegetation were cleared away prior to sampling, and small pits were dug to a depth of $20 \mathrm{~cm}$. Surface soil samples $(0-20 \mathrm{~cm})$ were collected by spade from the pit walls. Soils were packaged and transported to the laboratory, where rocks, surface litter, and root materials were removed while soil clods were broken by hand and passed through an 8 -mm sieve. Soils were then air-dried, passed through a 2-mm sieve, and stored at room temperature. Soil carbonates were removed from an aliquot of each sample by the acid fumigation technique (Harris et al. 2001; Komada et al. 2008). Briefly, $25 \mu \mathrm{L}$ of deionized water were added to $15 \mathrm{mg}$ of soil in a ceramic crucible, and exposed to the vapors of concentrated $\mathrm{HCl}$ in a sealed glass desiccator for $48 \mathrm{hr}$. After fumigation, samples were oven-dried at $50^{\circ} \mathrm{C}$ for $24 \mathrm{hr}$ to remove residual moisture.

Simultaneous thermal analyses (i.e. TG and DSC) were performed on both untreated and acid-fumigated aliquots of each sample according to the methods of Fernández et al. (2012) at the University of Pennsylvania. Briefly, $\sim 30 \mathrm{mg}$ of each sample were subjected to a constant $5^{\circ} \mathrm{C} / \mathrm{min}$ temperature ramp from ambient to $800^{\circ} \mathrm{C}$ in a Netzsch STA 409PC simultaneous thermal analyzer under a con- 


\section{Distribution of ${ }^{14} \mathrm{C}$ Ages in SOM by Thermal Fractionation}

tinuous flow of $\mathrm{CO}_{2}$-free gas $\left(30 \mathrm{~mL} / \mathrm{min}\right.$ of Ultra-Zero air and $10 \mathrm{~mL} / \mathrm{min}$ of $\mathrm{N}_{2}$ as a protective gas). The $\mathrm{CO}_{2}$ evolved during combustion of the sample was quantified downstream by a LICOR LI-840 infrared gas analyzer. The ensuing patterns of $\mathrm{CO}_{2}$ concentrations released from the samples as a function of temperature (i.e. "thermogram") were analyzed for dominant populations of carbon by peak deconvolution using the autofitting by residuals option and the Gaussian-Lorentzian sum (amplitude) peak function in PeakFit ${ }^{\circledR}$ v 4.12 (Systat Software, Inc.).

Fractions of pure $\mathrm{CO}_{2}$ were also collected for ${ }^{14} \mathrm{C}$ analyses during identical ramped-temperature combustions via modifications to a custom thermal analyzer ("dirt burner"; Rosenheim et al. 2008) developed at the National Ocean Sciences Accelerator Mass Spectrometry (NOSAMS) facility at the Woods Hole Oceanographic Institution. Modifications include i) a new gas handling system that provides steady, reproducible streams of $\mathrm{He}$ and $\mathrm{O}_{2}$; ii) a new control system that stabilizes the temperature ramp to $\pm<0.2{ }^{\circ} \mathrm{C} / \mathrm{min}$ over the working range $\left(200-1000{ }^{\circ} \mathrm{C}\right)$; iii) a custom quartz reactor designed for oxidation, rather than pyrolysis, of organic matter; and iv) upgrades to valves and plumbing that has reduced the methodological blank to $<4 \mu \mathrm{g} \mathrm{C}$ (i.e. $\sim 0.2 \%$ of sample mass). The analyzer was also coupled to a new fraction-collecting device, in which successive fractions of $\sim 324 \mu \mathrm{g} \mathrm{C}-\mathrm{CO}_{2}$ produced during ramped oxidation were isolated cryogenically in novel flowthrough glass traps. The ${ }^{14} \mathrm{C}$ content of each fraction of $\mathrm{CO}_{2}$ was quantified on the same day using NOSAMS' gas ion source (GIS) continuous-flow accelerator mass spectrometer (Roberts et al. 2011). Bulk AMS ${ }^{14} \mathrm{C}$ values of the untreated samples were measured separately at the National Isotope Centre, New Zealand. All ${ }^{14} \mathrm{C}$ measurements were blank-corrected and reported according to the conventions of Stuiver and Polach (1977). The fumigated samples were not submitted for bulk ${ }^{14} \mathrm{C}$ analyses because of concerns raised about the integrity of the SOM after fumigation as revealed by the results of thermal analysis (see below). Instead, we compare the mass-balanced cumulative Fm values of each sample, based on fraction modern carbon $(\mathrm{Fm})$ measurements and integrated thermogram areas (i.e. proportional to mass) of each fraction of $\mathrm{CO}_{2}$, with errors propagated from measurement uncertainties and an assumed 5\% uncertainty on integrated thermogram areas.

\section{RESULTS AND DISCUSSION}

The concentrations of $\mathrm{CO}_{2}$ released during ramped oxidation of untreated soils from both land uses revealed several discernable peaks that evolved primarily between 200 and $750{ }^{\circ} \mathrm{C}$ (Figure 1a,b; black curves). Specifically, both thermograms exhibited inflection points near $290{ }^{\circ} \mathrm{C}$ and local maxima at approximately 350,420 , and $490{ }^{\circ} \mathrm{C}$. Whereas the native sample produced 1 additional minor peak above $600^{\circ} \mathrm{C}$, a significant proportion of the cultivated sample's total carbon peaked in production at $\sim 697^{\circ} \mathrm{C}$. Peak deconvolution (Figure 1a,b; multicolored curves) suggests these features are indicative of 5 or 6 dominant populations of carbon with unique oxidation kinetics in the native and cultivated soils, respectively. Collectively, these patterns of $\mathrm{CO}_{2}$ released during ramped oxidation suggest that both soils were complex mixtures of molecules that clustered into groups characterized by thermochemical reactivities.

Based on soil $\mathrm{pH}$ values (7.5) and DSC measurements of net endothermic energy flows (data not shown), the highest temperature peaks $\left(>\sim 600^{\circ} \mathrm{C}\right)$ in Figure 1a,b were attributed to the presence of soil carbonates. These peaks all but disappeared upon acid fumigation (Figure 1c,d), providing further evidence for carbonates. Campbell et al. (1997) describe the native soil as "overlying a high lime, massive gray $\mathrm{B}_{2}$ horizon" at $\sim 30 \mathrm{~cm}$ depth. The increased carbonate contribution to the thermogram of the cultivated soil is likely attributable to carbonate entrained upwards into the topsoil during tillage turbation. While the general shape of the thermograms (i.e. number and positions of peaks) was relatively similar, large differences in the relative proportions of peak heights and areas 


\section{A F Plante et al.}
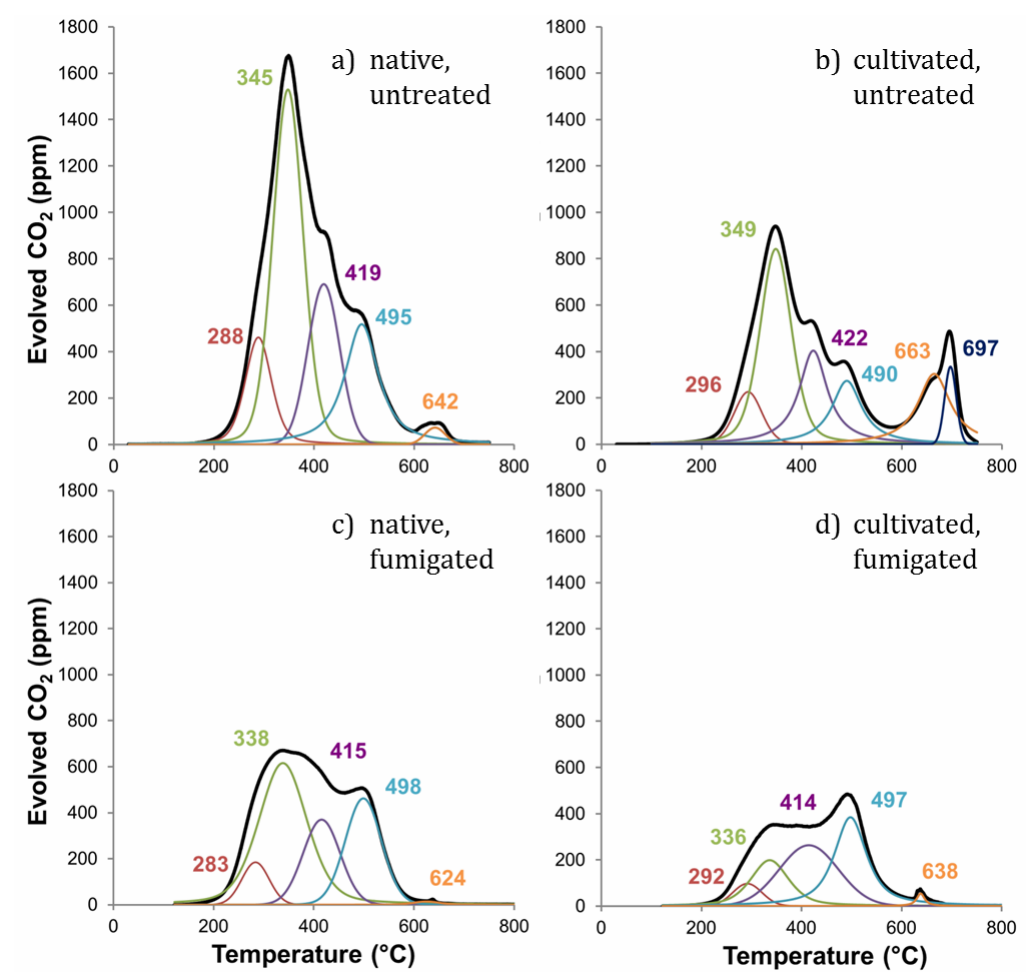

Figure 1 Total $\mathrm{CO}_{2}$ evolution (black curve) and peak deconvolution (color curves) during ramped-temperature oxidation $\left(5^{\circ} \mathrm{C} / \mathrm{min}\right.$ ) of untreated (a) native and (b) cultivated samples and acid-fumigated (c) native and (d) cultivated samples. High-temperature peaks (> $\sim 600^{\circ} \mathrm{C}$ ) correspond to the presence of soil carbonates.

suggest that the SOM in the native and cultivated soils was compositionally unique, and that soil carbon composition was sensitive to land-use practices (Table 1). For instance, the amplitude of the largest peak $\left(\sim 342{ }^{\circ} \mathrm{C}\right)$ associated with SOM combustion $\left(<\sim 600{ }^{\circ} \mathrm{C}\right)$ decreased from $1505 \mathrm{ppm}$ $\mathrm{CO}_{2}$ in the untreated soil under native vegetation to $866 \mathrm{ppm} \mathrm{CO}_{2}$ in the untreated soil under longterm cultivation, which is largely a function of soil $\mathrm{C}$ content. However, the relative proportion of the total area contributed by the largest peak increased from $43.5 \%$ in the untreated native soil to $50.8 \%$ in the untreated cultivated soil, suggesting that a significant proportion of thermally labile organic matter was lost through decomposition and reduced inputs.

Table 1 Amplitudes and (relative peak areas) ${ }^{\mathrm{a}}$ of deconvoluted thermograms associated with the combustion of soil organic matter during ramped-temperature oxidation $\left(5^{\circ} \mathrm{C} / \mathrm{min}\right)$ of soil samples.

\begin{tabular}{|c|c|c|c|c|}
\hline Approximate peak center ${ }^{b}$ & $290^{\circ} \mathrm{C}$ & $342^{\circ} \mathrm{C}$ & $418^{\circ} \mathrm{C}$ & $495^{\circ} \mathrm{C}$ \\
\hline Native soil, untreated (\%) & $486(13.0)$ & $1505(43.5)$ & $705(20.3)$ & $518(21.9)$ \\
\hline Native soil, fumigated (\%) & $184(7.2)$ & 615 & $369(19.6)$ & $462(24.3)$ \\
\hline Cultivated soil, untreated (\%) & $196(8.2)$ & $866(50.8)$ & $380(22.7)$ & $276(18.2)$ \\
\hline Cultivated soil, fumigated (\%) & $96(6.3)$ & $198(20.4)$ & $263(34.3)$ & $384(37.6)$ \\
\hline
\end{tabular}

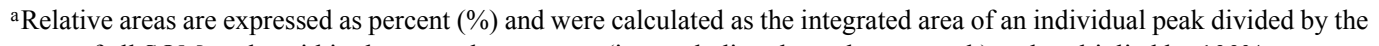
area of all SOM peaks within the same thermogram (i.e. excluding the carbonate peak) and multiplied by $100 \%$.

${ }^{\mathrm{b}}$ Approximate peak centers are listed as the average peak center for analogous peaks among all 4 treatments. See Figure 1 for actual peak center temperatures. 
In contrast to untreated soils (Figure 1a,b), thermograms of acid-fumigated soils did not exhibit readily discernable peaks (Figure 1c,d; black curves). This loss of chemical fidelity as detected on the Netzsch thermal analyzer was reproducibly observed upon combusting separate aliquots of untreated and fumigated samples (Figures 2a,b and 2c,d, respectively; black curves) with NOSAMS' custom thermal analyzer. The distorted thermograms of fumigated samples were therefore not an artifact of the instruments employed, but rather were indicative of alterations to chemical compositions or thermal reactivities of the original constituents. While the disappearance of the highest temperature peaks and decreases in total $\mathrm{C}$ concentrations measured by elemental analysis before and after acid fumigation (e.g. 2.6\% relative decrease in soils under native vegetation, and $13.6 \%$ decrease in soils under long-term cultivation) were consistent with carbonate removal by acid fumigation (Figure 1b,d), apparent changes in residual organic matter thermal oxidation kinetics demonstrated that this treatment was not selective. For instance, the amplitude of the largest peak $\left(\sim 342{ }^{\circ} \mathrm{C}\right)$ of the soil under native vegetation decreased from $1505 \mathrm{ppm} \mathrm{CO}_{2}$ before acid fumigation to $615 \mathrm{ppm} \mathrm{CO}_{2}$ after fumigation (Table 1). The proportion of the total area of this peak also increased from $43.5 \%$ in the untreated soil to $48.4 \%$ in the fumigated soil. These alterations are likely attributable to the hydrolysis of SOM by the $\mathrm{HCl}$ vapors that would act preferentially on the thermally labile fraction, and may explain previously observed sensitivities in chemical and stable isotope measurements to acidification of organic matter (Brodie et al. 2011).
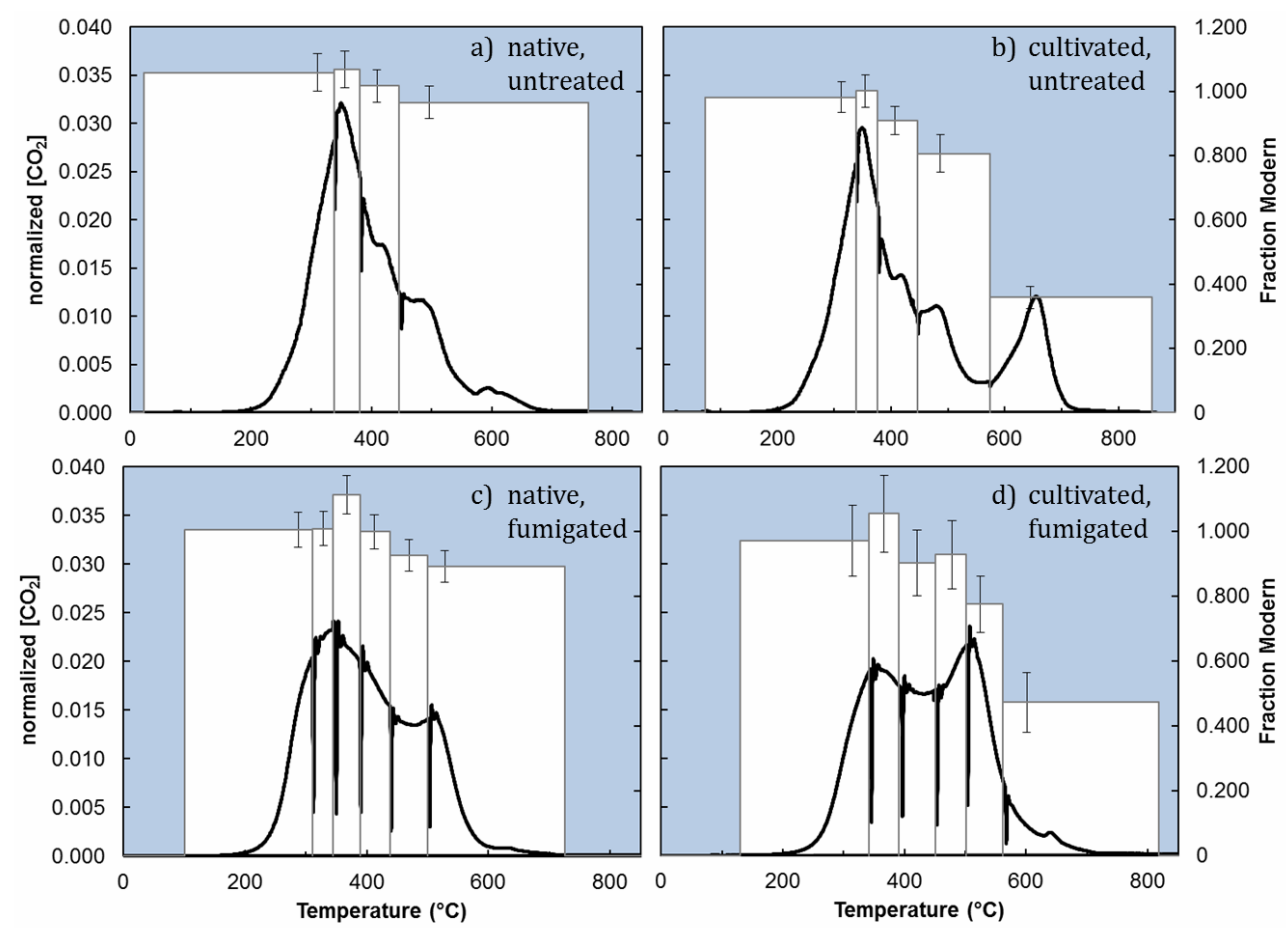

Figure 2 Normalized thermograms (black curve) of $\mathrm{CO}_{2}$ concentration from the untreated (a) native and (b) cultivated samples and acid-fumigated (c) native and (d) cultivated, each superimposed on histograms of corresponding ${ }^{14} \mathrm{C}$ data (bars spanning temperatures over which fractions were collected). Error bars $( \pm 2 \sigma)$ are located above the temperature corresponding to the median mass of $\mathrm{C}$ evolved for each fraction. 


\section{A F Plante et al.}

The untreated native soil possessed a bulk fraction Fm value of $0.944 \pm 0.003$. The thermally isolated fractions decreased slightly from $1.059 \pm 0.029$ to $0.965 \pm 0.025$ with increasing temperature (Figure 2a), and resulted in a mass-balanced cumulative value of $1.030 \pm 0.021 \mathrm{Fm}$. The near uniformity of these ${ }^{14} \mathrm{C}$ values across a broad range of reaction temperatures implies that the native soil constituents were almost equally persistent despite possessing a range of thermochemical stabilities. In contrast, the cultivated sample possessed a bulk Fm of $0.790 \pm 0.002$. The thermally isolated fractions decreased significantly from $0.982 \pm 0.024$ at low temperatures to $0.358 \pm 0.018$ above $574{ }^{\circ} \mathrm{C}$ (Figure 2b), and resulted in a mass-balanced cumulative Fm of $0.825 \pm 0.018$. Since acid fumigation largely eliminated the $\mathrm{CO}_{2}$ peak at $>\sim 600{ }^{\circ} \mathrm{C}$, we might prematurely attribute the decrease in bulk ${ }^{14} \mathrm{C}$ values with cultivation to the incorporation of ${ }^{14} \mathrm{C}$-depleted carbonates. However, the ${ }^{14} \mathrm{C}$ depleted signature of this thermal region was retained after acid fumigation (Figure 2b,d). The cause of the decrease in ${ }^{14} \mathrm{C}$ values for the thermal fraction $>\sim 600{ }^{\circ} \mathrm{C}$, which drives the decrease in bulk ${ }^{14} \mathrm{C}$ values, is unclear at this point. It is likely attributable to changes in SOM decomposability of the residual SOM after long-term cultivation, which is a combination of changes in chemical composition as well as changes in mineral association, both of which strongly affect the combustion pattern observed during thermal analysis. Strong mineral association has previously been demonstrated to increase the temperatures at which various organic moieties are observed in pyrolysis studies (e.g. Leinweber and Schulten 1999). Finally, despite dramatic alterations to the pattern of $\mathrm{CO}_{2}$ released by individual populations of carbon, acid fumigation did not significantly alter the coarse ${ }^{14} \mathrm{C}$ spectra of either the native or cultivated samples (Figure 2a,c, and 2b,d), or their mass-balanced cumulative Fm values $(0.995 \pm 0.011$ and $0.890 \pm 0.022$, respectively). This suggests that while acid fumigation may have altered the composition or organo-mineral configuration of the SOM, it had a minimal effect on its isotopic signature. This observation is consistent with a similar observation of $\delta^{13} \mathrm{C}$ values of SOM before and after acid fumigation (e.g. Ramnarine et al. 2011).

\section{CONCLUSIONS}

The goal of this study was to demonstrate the proof of principle for the coupling of oxidative thermal and ${ }^{14} \mathrm{C}$ analyses as a method to characterize the spectrum of SOM stability better than a single bulk

${ }^{14} \mathrm{C}$ value can. Contrary to our hypothesis, and with the exception of the $>\sim 600{ }^{\circ} \mathrm{C}$ region, thermal fractionation did not unequivocally reveal thermally labile SOM that is younger. That being said, the method does generate a rapid fingerprint of the chemical and isotopic composition of SOM that varies dramatically with differences in land-use practices, thus providing novel insights into SOM dynamics. Although acid fumigation does not significantly alter the ${ }^{14} \mathrm{C}$ spectrum of SOM, it clearly modifies the pattern of $\mathrm{CO}_{2}$ release during ramped oxidation. Therefore, the most representative and detailed thermograms are obtained by analyzing untreated soil samples. While direct attribution of ${ }^{14} \mathrm{C}$ values to individual peaks is somewhat confounded by overlapping temperature ranges for oxidation of unique populations of carbon, in general, thermally stable fractions of SOM appear to be ${ }^{14} \mathrm{C}$-depleted compared to thermally reactive (low temperature) fractions regardless of pretreatment.

\section{ACKNOWLEDGMENTS}

This project was supported by NIFA-USDA grant 2010-65107-20351 (Plante) and Cooperative Agreement OCE-2310753487 with the US National Science Foundation (Roberts, Beaupré). New Zealand public research funds provided support through GNS Science (GCT) (Baisden). 


\section{Distribution of ${ }^{14} \mathrm{C}$ Ages in SOM by Thermal Fractionation}

\section{REFERENCES}

Brodie CR, Leng MJ, Casfor JSL, Kendrick CP, Lloyd JM, Yongqiang Z, Bird MI. 2011. Evidence for bias in $\mathrm{C}$ and $\mathrm{N}$ concentrations and $\delta^{13} \mathrm{C}$ composition of terrestrial and aquatic organic materials due to pre-analysis acid preparation methods. Chemical Geology 282(3-4):67-83.

Campbell CA, Lafond GP, Moulin AP, Townley-Smith L, Zentner RP. 1997. Crop production and soil organic matter in long-term crop rotations in the sub-humid Northern Great Plains of Canada. In: Paul EA, Paustian K, Elliott ET, Cole CV, editors. Soil Organic Matter in Temperate Agroecosystems. Boca Raton: CRC Press Inc. p 297-315.

Denef K, Plante AF, Six J. 2009. Characterization of soil organic matter. In: Kutsch W, Bahn M, Heinemeyer A, editors. Soil Carbon Dynamics: An Integrated Methodology. London: Cambridge University Press. p 91126.

Dorodnikov M, Fangmeier A, Kuzyakov Y. 2007. Thermal stability of soil organic matter pools and their $\delta^{13} \mathrm{C}$ values after $\mathrm{C}_{3}-\mathrm{C}_{4}$ vegetation change. Soil Biology \& Biochemistry 39(5):1173-80.

Fernández JM, Peltre C, Craine JM, Plante AF. 2012. Improved characterization of soil organic matter by thermal analysis using $\mathrm{CO}_{2} / \mathrm{H}_{2} \mathrm{O}$ evolved gas analysis. Environmental Science \& Technology 46(16):8921-7.

Harris D, Horwath WR, van Kessel C. 2001. Acid fumigation of soils to remove carbonates prior to total organic carbon or carbon-13 isotopic analysis. Soil Science Society of America Journal 65(6):1853-6.

Komada T, Anderson MR, Dorfmeier CL. 2008. Carbonate removal from coastal sediments for the determination of organic carbon and its isotopic signatures, $\delta^{13} \mathrm{C}$ and $\Delta^{14} \mathrm{C}$ : comparison of fumigation and direct acidification by hydrochloric acid. Limnology and Oceanography Methods 6:254-62.

Leinweber P, Schulten HR. 1999. Advances in analytical pyrolysis of soil organic matter. Journal of Analytical and Applied Pyrolysis 49(1-2):359-83.

Lopez-Capel E, Abbott GD, Thomas KM, Manning DAC. 2006. Coupling of thermal analysis with quadrupole mass spectrometry and isotope ratio mass spectrometry for simultaneous determination of evolved gases and their carbon isotopic composition Journal of Analytical and Applied Pyrolysis 75(2):829.

Manning DAC, Lopez-Capel E, White ML, Barker S. 2008. Carbon isotope determination for separate components of heterogeneous materials using coupled thermogravimetric analysis/isotope ratio mass spec- trometry. Rapid Communications in Mass Spectrometry 22(8):1187-95.

Murage EW, Voroney P, Beyaert RP. 2007. Turnover of carbon in the free light fraction with and without charcoal as determined using the ${ }^{13} \mathrm{C}$ natural abundance method. Geoderma 138(1-2):133-43.

Paul EA, Morris SJ, Conant RT, Plante AF. 2006. Does the acid hydrolysis-incubation method measure meaningful soil organic carbon pools? Soil Science Society of America Journal 70(3):1023-35.

Plante AF, Fernández JM, Haddix ML, Steinweg JM, Conant RT. 2011. Biological, chemical and thermal indices of soil organic matter stability in four grassland soils. Soil Biology \& Biochemistry 43(5):1051-8.

Ramnarine R, Voroney RP, Wagner-Riddle C, Dunfield KE. 2011. Carbonate removal by acid fumigation for measuring the $\delta^{13} \mathrm{C}$ of soil organic carbon. Canadian Journal of Soil Science 91(2):247-50.

Roberts ML, von Reden KF, McIntyre CP, Burton JR. 2011. Progress with a gas-accepting ion source for Accelerator Mass Spectrometry. Nuclear Instruments and Methods in Physics Research B 269(24):3192-5.

Rosenheim BE, Day MB, Domack E, Schrum H, Benthien A, Hayes JM. 2008. Antarctic sediment chronology by programmed-temperature pyrolysis: Methodology and data treatment. Geochemistry, Geophysics, Geosystems 9(4): Q04005, doi:10.1029/ 2007GC001816.

Smith JU, Smith P, Monaghan R, MacDonald J. 2002. When is a measured soil organic matter fraction equivalent to a model pool? European Journal of Soil Science 53(3):405-16.

Stuiver M, Polach HA. 1977. Discussion: reporting of ${ }^{14} \mathrm{C}$ data. Radiocarbon 19(3):355-63.

Trumbore S. 2009. Radiocarbon and soil carbon dynamics. Annual Review of Earth and Planetary Sciences 37(1):47-66.

Trumbore SE, Zheng SH. 1996. Comparison of fractionation methods for soil organic matter ${ }^{14} \mathrm{C}$ analysis. $R a-$ diocarbon 38(2):219-29.

von Lützow M, Kögel-Knabner I, Ekschmitt K, Flessa H, Guggenberger G, Matzner E, Marschner B. 2007. SOM fractionation methods: relevance to functional pools and to stabilization mechanisms. Soil Biology \& Biochemistry 39(9):2183-207.

Wang S-L, Burr GS, Chen Y-G, Lin Y, Wu T-S. 2013. Low-temperature and temperature stepped-combustion of terrace sediments from Nanfu, Taiwan. Radiocarbon, these proceedings, doi:10.2458/ azu_js_rc.55.16285. 